\title{
The use of an online thoracic surgery curriculum: A win-win situation
}

\author{
Lisa M. Brown, MD, MAS
}

\author{
From the Division of Cardiothoracic Surgery, Department of Surgery, University of California Davis Health, Sac- \\ ramento, Calif. \\ Disclosures: Author has nothing to disclose with regard to commercial support. \\ Received for publication April 5, 2018; accepted for publication April 9, 2018; available ahead of print May 10, \\ 2018. \\ Address for reprints: Lisa M. Brown, MD, MAS, UC Davis Health, 2221 Stockton Blvd, Room 2115, Sacramento, \\ CA 95817 (E-mail: lmbrown@ucdavis.edu). \\ J Thorac Cardiovasc Surg 2018;156:920-1 \\ $0022-5223 / \$ 36.00$ \\ Copyright $(2) 2018$ by The American Association for Thoracic Surgery \\ https://doi.org/10.1016/j.jtcvs.2018.04.033
}

The first residency programs required physicians in training to reside in an established teaching hospital full-time. These residents worked long hours, adhered to a strict hierarchy, and learned the science and art of medicine under the guidance of master clinicians devoted to teaching. Graduate medical education in the era between the world wars has been referred to as the "educational era," during which the highest priority of teaching hospitals was education. ${ }^{1}$ Fast forward to the current era, defined by resident work hour restrictions, increasing complexity of patient care, and health care systems focused on increased throughput of patients. Moreover, in this era of value-based care, there is greater scrutiny and transparency with regard to patient outcomes. These changes, although in the best interest of the patient, pose a challenge to the education of surgical trainees.

Surgical education experts have responded in several ways, one of which is development of e-learning, or learning conducted by means of electronic media. ${ }^{2}$ The advantages of e-learning include easily accessible information that can be readily updated and the fact that trainees may learn at their own pace and are provided with self-assessments. ${ }^{2}$ Importantly, e-learning is better than no education intervention and is as effective as traditional didactics, and education experts suggest that the focus should now be on determining the most efficient use of e-learning.

Education experts in cardiothoracic surgery have developed an online Thoracic Surgery Curriculum as a collaboration of the American Board of Thoracic Surgery, the Joint Council for Thoracic Surgical Education, and the Thoracic Surgery Directors Association. ${ }^{4}$ This curriculum, implemented in 2013, includes an extensive set of teaching modules and a list of cognitive expectations of residents on completion of training. This curriculum has been put to the test: cardiothoracic surgical trainees who used the online curriculum more frequently had

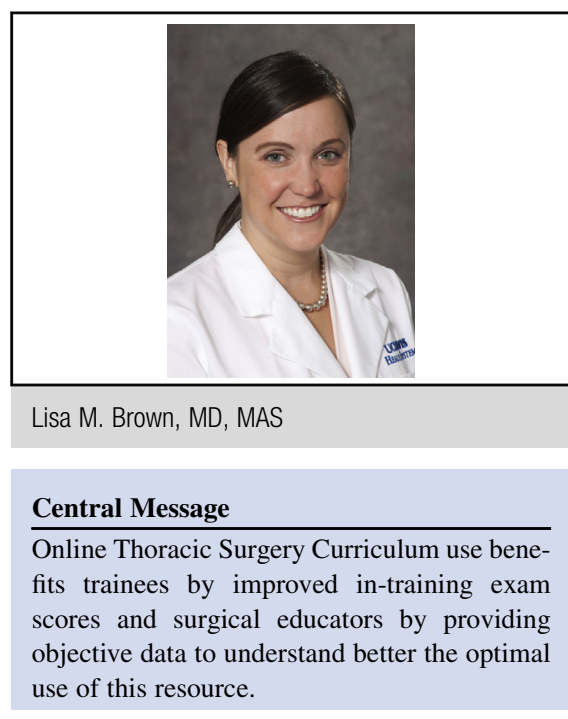

See Article page 922. greater improvement on the in-training examination than did those who used it less frequently. ${ }^{5}$ In this issue of the Journal, Luc and colleagues ${ }^{6}$ further investigated the study habits of cardiothoracic surgical trainees, as defined by login frequency to the online Thoracic Surgery Curriculum, and the impact of these habits on performance on the in-training exam. The highest-scoring trainees and those who improved the most from the previous year used the curriculum more frequently in the final month, which was a win for those trainees who frequented the online curriculum. The other win with regard to elearning is the opportunity for surgical education experts to gather objective data regarding trainee use of resources, including frequency of use, total time spent using the curriculum, specific content and modules accessed, and selfassessment scores. With more granular data on exactly how trainees use e-learning resources and how their use affects not only in-training examination scores but also overall clinical performance, we can better understand the most efficient use of e-learning for cardiothoracic surgical trainees.

\section{References}

1. Goitein L. Training young doctors: the current crisis. The New York Review of Books. Available at: www.nybooks.com/articles/2015/06/04/training-youngdoctors-current-crisis. Accessed April 4, 2018. 
2. Evgeniou E, Loizou P. The theoretical base of e-learning and its role in surgical education. J Surg Educ. 2012;69:665-9.

3. Cook D, Levinson A, Garside S, Dupras D, Erwin PJ, Montori V. Internet-based learning in the health professions: a meta-analysis. JAMA. 2008;300:1181-96.

4. Antonoff MB, Verrier ED, Yang SC, Lin J, Dearmond DT, Allen MS, et al. Online learning in thoracic surgical training: promising results of multi-institutional pilot study. Ann Thorac Surg. 2014;98:1057-63.
5. Antonoff MB, Verrier ED, Allen MS, Aloia L, Baker C, Fann JI, et al. Impact of Moodle-based online curriculum on thoracic surgery in-training examination scores. Ann Thorac Surg. 2016;102:1381-6.

6. Luc JG, Verrier ED, Allen MS, Aloia L, Baker C, Fann JI, et al. Does cramming work? Impact of national web-based thoracic surgery curriculum login frequency on thoracic surgery in-training exam performance. J Thorac Cardiovasc Surg. 2018;156:922-7. 